\title{
Proline Measurement
}

National Cancer Institute

\section{Source}

National Cancer Institute. Proline Measurement. NCI Thesaurus. Code C122141.

The determination of the amount of proline present in a sample. 